\title{
ADOPSI TEKNOLOGI MUSLIM, SIKAP, DAN INTENSI PEMBELIAN PRODUK INVESTASI ISLAM MENGGUNAKAN FINANCIAL TECHNOLOGY
}

Maulia Nurul, R. Gratiyana Ningrat maulia.nurul@ui.ac.id,r.gratiyana@ui.ac.id

Ekonomi dan Keuangan Islam, Kajian Timur Tengah dan Islam, Universitas Indonesia

Received: 13 September 2018

Final Acepted: 15 November

Published Online: Desember 2018

Keywords:

Technology Adoption, Buying

Behaviour, Buying Intention, Islamic

Investment, Financial Technology,

SEM

Corresponding Authors:

Maulia Nurul

\section{Abstract}

The purpose of this research is to examines the muslim's buying behavior in Islamic Financial Technology products based on their technology adoption. The Structural Equation Model (SEM) proves that there's significant relationship between Technology Adoption to construct the Buying Attitude. Meanwhile, the Technology Adoption has significant relationship directly to Buying Intention which means the partial mediation of attitude occurs in this model. The Buying Attitude towards Islamic Financial Technology products show significant relationship to buying intention to adopt the Islamic investment products in the future

\begin{abstract}
ABSTRAK
Tujuan dari penelitian ini adalah untuk menguji perilaku pembelian Muslim dalam produk Teknologi Keuangan Islam berdasarkan adopsi teknologi mereka. The Structural Equation Model (SEM) membuktikan bahwa ada hubungan yang signifikan antara adopsi teknologi untuk membangun sikap pembelian atau menggunakan. Sementara itu, adopsi teknologi memiliki hubungan yang signifikan secara langsung dengan keinginan membeli yang berarti mediasi parsial sikap terjadi dalam model ini. Sikap pembelian terhadap produk Teknologi Keuangan Islam menunjukkan hubungan yang signifikan dengan niat membeli untuk mengadopsi produk investasi Islam di masa depan.
\end{abstract}

Kata Kunci: Adopsi Teknologi, Sikap Pembelian, Intensi Pembelian, Investasi Islam, Teknologi Finansial

\section{PENDAHULUAN}

Di era digitalisasi, akselerasi inovasi financial technology memiliki potensi besar untuk membuat ekonomi tumbuh berkembang dan semakin memberikan manfaat kepada masyarakat. Meluas dan mudahnya penggunaan teknologi internet dengan penggunaan 
gadget atau smartphone diikuti dengan perkembangan layanan inovasi teknologi memberikan utilitas bagi masyarakat dari segi efisiensi waktu dan efisiensi biaya. Di Amerika Serikat, pengadopsian fintech telah meningkat dua kali lipat sejak 2015. Mayoritas masyarakat merasa nyaman dengan teknologi sehingga beralih ke perusahaan fintech (Shorfer, 2017).

Secara umum dan dalam arti luas, fintech menunjuk pada penggunaan teknologi untuk memberikan solusi-solusi keuangan (Arner, et al, 2015). Secara spesifik, fintech didefinisikan sebagai aplikasi teknologi digital untuk intermediasi masalah-masalah keuangan (Aaron, et al, 2017). Layanan jasa keuangan pada fintech diklasifikasi ke dalam empat kategori, yaitu pembayaran, transfer, kliring dan penyelesaian (FSB, 2017). Keempat jenis fintech diciptakan berdasarkan permintaan masyakarat agar aplikasi tersebut dapat diterima dalam keseharian masyarakat itu sendiri. Beberapa tahun belakangan masyarakat diperkenalkan dengan alternatif untuk mendapatkan akses keuangan berupa pendanaan di luar sumber pendanaan yang sudah umum seperti perbankan dan pasar modal. Alternatif pendanaan tersebut dikenal dengan istilah crowdfunding (Arifin et. al, 2017). Kini, istilah investasi dengan crowdfunding dan peer to peer meluas di kalangan masyarakat hingga kemudian muncul banyaknya fintech yang menciptakan produk keuangan jenis tersebut.

Pemilihan dan pelaksanaan transaksi investasi yang dilakukan harus sejalan dengan prinsip kehati-hatian (prudential management) dan menghindari spekulasi uang di dalamnya mengandung unsur gharar, riba dan maysir. Maka dalam pemilihan produk keuangan, prinsip-prinsip yang harus diperhatikan tentang halal haramnya produk tersebut. Investasi syariah berfungsi sebagai intermediaries yang membantu surplus unit melakukan penempatan dana untuk diinvestasikan (Asytuti, 2013). Dengan tersedianya teknologi kemudian dapat memudahkan kerja sistem di tengah layanan investasi produk keuangan.

Dengan adanya perkembangan teknologi finansial tersebut, di sisi lain para pengusaha startup dan UKM dapat menggalang dana tanpa diwajibkan pembayaran bunga dan pokok investasi dengan adanya sistem equity crowdfunding. Perusahaan teknologi, dengan kemudahan teknologi ini, dapat menghubungkan antara populasi yang unbanked dan UKM atau pihak yang membutuhkan modal. Crowdfunding sendiri mengambil keuntungan dari pengambilan keputusan dan inovasi berbasis keramaian kemudian 
menerapkannya pada pendanaan proyek usaha (Thaker, 2018). Peningkatan modal dengan cara ini telah terbukti di banyak negara, seperti Australia, Amerika Serikat, Kanada, Belanda, Inggris, Prancis, India, dan Brazil. Pengadopsian fintech meningkat pesat karena alasan yang sederhana, yaitu perusahaan teknologi keuangan memenuhi kebutuhan pelanggan. Di Cina, 69 persen dari populasi menggunakan layanan teknologi keuangan. India juga memiliki tingkat adopsi yang tinggi, dengan 52 persen penduduknya menggunakan layanan teknologi keuangan (Shorfer, 2017).

Dalam Survei Global Fintech PwC, responden industri perbankan menyatakan bahwa seperempat dari bisnis mereka, atau lebih, dapat berisiko hilang ke perusahaan Fintech yang berdiri sendiri dalam lima tahun. Tujuh investasi global di Fintech menghabiskan lebih dari tiga kali lipat pada tahun 2014 dan mencapai lebih dari \$ 12 miliar. Sebagai perbandingan, bank menghabiskan sekitar \$ 215 miliar untuk TI di seluruh dunia pada tahun 2014 (PWC Research, 2017). Jumlah dana yang telah dihabiskan tersebut digunakan untuk infrastruktur informasi seperti hardware, software, service internal dan service eksternal dan pemasaran produk demi menarik minat masyarakat terhadap produk industri.

Data di atas menunjukkan bahwa kemajuan teknologi keuangan yang cukup substansial bagi hasrat masyarakat tidak memerlukan modal besar seperti yang dilakukan oleh industri perbankan. Pada praktiknya, perusahaan berteknologi tinggi memiliki potensi besar untuk menurunkan biaya dan menawarkan layanan produk yang lebih baik untuk masyarakat. Pencetus teknologi keuangan hari ini menggunakan model online-only untuk menjangkau generasi milenium dan juga segmen lainnya. Namun, perkembangan yang pesat ini tidak berarti dapat menjangkau seluruh elemen masyarakat. Menurut data dari Bank Indonesia, jumlah pengguna internet berumlah 88,1 juta atau setara 34 persen dari jumlah penduduk. Jumlah pengguna internet yang aktif berkisar 64,1 juta orang. Sedangkan 66 persen masih belum menjangkau penggunaan internet karena sebab-sebab yang beragam.

Oleh karena itu dapat dikatakan bahwa pengembangan teknologi informasi dalam hal investasi memerlukan sumber pembiayaan inovatif sebaik-baiknya. Dengan demikian, mekanisme baru yang akan digunakan untuk sumber pembiayaan investasi diperlukan untuk pengembangan usaha milik muslim lainnya seperti peer to peer lending syariah atau crowdfunding syariah dengan pengenalan yang baik pada masyarakat. 
Penelitian ini akan mendiskusikan dengan layanan finansial teknologi yang penghimpunan dananya berbeda dengan sumber dana dari lembaga keuangan pada umumnya dengan penggunaan teknologi finansial. Tujuan dari makalah ini adalah untuk memberikan tinjauan literatur empiris dari studi tentang kegunaan yang dirasakan pada fintech, persepsi kemudahan penggunaan, terhadap niat pembelian (penggunaan), sikap pembelian dan adopsi teknologi tentang investasi syariah menggunakan teknologi finansial.

\section{KAJIAN TEORI}

\section{Konsep Teknologi Finansial}

Perkembangan teknologi digital yang semakin maju membentuk model-model baru di bidang keuangan. Model baru jasa pelayanan keuangan yang memanfaatkan kecanggihan teknologi populer dengan istilah financial technology atau fintech (Arifin, 2017). Contoh inovasi sekaligus pemanfaatan teknologi di bidang keuangan yang memudahkan penggunanya dalam mengakses kebutuhan terhadap jasa-jasa keuangan seperti mobile banking, marketplace, dompet digital, dan crowdfunding.

Kemajuan finansial teknologi merupakan kontributor yang sangat diperlukan untuk meningkatkan efisiensi sistem keuangan dan cara sistem keuangan yang berlaku mempengaruhi pertumbuhan ekonomi (Tallo, 2001). Perusahaan Fintech menyadari masalah apa yang dialami konsumen dengan perusahaan jasa keuangan tradisional. Masalah dengan biaya tinggi, pelayanan yang buruk, transfer yang lambat, dan kurangnya akses menciptakan peluang emas untuk startup. Di Cina, baik konsumen dan bisnis telah berjuang untuk mendapatkan layanan dari bank tradisional. Di masa lalu, mereka harus melakukannya tanpa layanan perbankan. Sekarang, perusahaan-perusahaan Fintech bersemangat untuk memenuhi kebutuhan mereka. Pola yang sama terjadi di pasar negara berkembang lainnya seperti Afrika Selatan, Brasil, dan Meksiko (Shorfer, 2017).

Fintech telah mengubah sistem pembayaran di masyarakat dan telah membantu perusahaan-perusahaan start-up dalam menekan biaya modal dan biaya operasional yang tinggi di awal. Dalam hal ini, fintech mampu menggantikan peran lembaga keuangan formal seperti bank. Dalam hal sistem pembayaran, fintech berperan dalam menyediakan pasar bagi pelaku usaha, menjadi alat bantu untuk pembayaran, penyelesaian/settlement dan kliring, 
membantu pelaksanaan investasi yang lebih efisien, mitigasi risiko dari system pembayaran yang konvensional serta membantu pihak yang membutuhkan untuk menabung, meminjam dana dan penyertaan modal ${ }^{1}$.

Berdasarkan data yang dilansir dari publikasi Bank Indonesia, jumlah pengguna internet berumlah 88,1 juta atau setara 34 persen dari jumlah penduduk. Jumlah pengguna internet yang aktif berkisar 64,1 juta orang. Selain itu, pertumbuhan pengguna mobile dan internet $8 \%$ per tahun. Indonesia menjadi pasar yang prospektif bagi fintech karena terus tumbuh baik dari sisi nilai transaksi dan jumlah pelaku. Tahun 2016 menuju tahun 2017, nilai transaksi tumbuh 24,6 persen yang awalnya 15,6 milyar menjadi 18,6 milyar ${ }^{2}$. Dalam menghadapi perkembangan teknologi informasi, para penyelenggara teknologi finansial oleh Bank Indonesia diwajibkan berkomitmen untuk mendorong inovasi dengan tetap memitigasi risiko yang muncul yaitu dengan menjaga keseimbangan antara keduanya.

\section{Produk Investasi Islam}

Muslim selalu didorong untuk terlibat dalam perdagangan dan berbagi dalam kemakmuran ekonomi. Mereka juga harus terlibat dalam aktivitas perdagangan yang sesuai dengan syariah Islam. Selain perdagangan, investasi dapat menjadi alternatif bagi muslim yang menginginkan perolehan pendapatan dari sumber dan cara yang bersih (Asytuti, 2003). Atensi masyarakat terhadap produk investasi dalam keuangan saat ini menjadi peluang besar bagi para startup digital yang menjadi mediasi antara pemilik modal dan pelaku usaha. Menurut Guyot (2014), tujuan yang ingin diperoleh dari dana seorang muslim adalah untuk menawarkan jasa investasi keuangan yang identik dengan dana konvensional sambil memastikan produk sesuai dengan hukum Islam, dengan cara yang sama seperti dana sosial atau etika dalam hal nilai-nilai moral yang serupa.

Filosofi perilaku investasi ekonomi konvensional yang lebih dituntun oleh kekuatan pasar memiliki perbedaan mendasar dengan investasi syariah yang lebih mengedepankan etika. Pilihan-pilihan dan bentuk-bentuk penilaian invetasi pun tidak hanya didasarkan pada dua

\footnotetext{
1 bi.go.id, Edukasi Financial Technology dalam https://www.bi.go.id/id/edukasi-perlindungankonsumen/edukasi/produk-dan-jasa-sp/fintech/Pages/default.aspx, diunduh Kamis 1 November 2018, pukul 11.00 2 Hadi, Rosmaya. Regulasi Ekonomi dalam Meningkatkan Pembangunan di Daerah dalam https://www.bi.go.id/id/institute/kegiatan/kuliah-umum/Contents/Materi Kuliah Umum USU.pptx diunduh Kamis 1 November 2018, pukul 13.40
} 
pertimbangan, yaitu risiko dan keuntungan, namun juga karakteristik dari perusahaan yang diinvestasikan. Konsep ethical investment versi barat dengan investasi syariah memiliki epistemologi yang berbeda karena Islam terlebih dahulu mengembangkan konsep muamalah yang tidak hanya berbasis keuntungan materi, namun juga immateril (Irkhami. 2010).

Dalam pelaksanaan perkembangan invetasi syariah, terdapat banyak Muslim yang tidak bersepakat dengan hadirnya produk keuangan ini sebab dalam fiqih muamalah investasi memiliki unsur gharar dan tadlis atau ketidakpastian. Namun, dalam literature keuangan lain disebutkan bahwa ketidakpastian meliputi risiko yang tidak dapat diperkirakan sebelumnya (unexpected risk). Sedangkan risiko dalam pasar investasi adalah jenis risiko yang dapat diprediksi. Hal ini berbeda pula dengan transaksi spekulasi dan judi yang memperoleh keuntungan tanpa memberikan kontribusi riil dalam perekonomian. Bahkan jika unsur spekulasi dan judi tumbuh di masyarakat, tercipat penyakit sosial dan merusak tatanan sosioekonomi. Pelarangan ini terdapat pada QS Al-Maidah: 90 dan Al-Baqoroh: 219.

Berdasarkan kecenderungan para investor, perilaku preferensi terhadap risiko secara garis besar dikategorikan menjadi tiga model (Sundjaja dan Barlian, 2002: 48), antara lain risk seeking sebagai pelaku yang berani mengambil risiko dinggi dengan harapan imbal hasil yang juga relatif tinggi (high risk high return), risk indifferent yaitu pelaku yang cukup berani mengambil risiko yang moderat dengan imbal hasil yang moderat pula (medium risk medium return), dan risk averse yaitu pelaku yang hanya berani mengambil risiko dalam tingkat yang relative rendah dengan imbal hasil yang juga relative rendah. Berdasarkan tujuan ini, investor sesungguhnya semua bersikap risk averse, sebab tidak ada seorangpun yang suka menerima risiko. Perbedaan antara investor dengan maysir atau gambling diisyaratkan dengan ketiga asumsi-asumsi di atas.

\section{Adopsi Teknologi, Niat, dan Sikap Pembelian}

Teknologi informasi dapat dilihat sebagai sebuah inovasi yang proses difusinya melibatkan dua sisi yaitu sisi penawaran (supply side) dan sisi permintaan (demand side) (Tornatzky dan Fleischer, 1990). Pada saat suatu perusahaan mengeluarkan sebuah produk layanan inovasi di pasar, salah satu hal yang menjadi perhatian prinsipil adalah bagaimana penerimaan masyarakat terhadap inovasi baru (Ario, 2007). Strategi peluncuran produk di pasar membutuhkan analisa penerimaan sehingga bisa memberikan kontribusi dan dampak 
yang baik terhadap masyarakat. Berdasarkan teori yang dikembangkan oleh Everett Rogers dan Geoffrey Moore mengenai Roger's five factors (Rogers, 1995), terdapat lima faktor yang dapat mempengaruhi penerimaan suatu inovasi pada pasar, yaitu kelebihan dari inovasi baru yang diluncurkan (relative advantage), kesesuaian inovasi baru dengan nilai-nilai dan kebiasaan masa kini (compatibility), tingkat kesulitan dalam menggunakan inovasi baru (complexity), dan tingkat kesulitan bagi calon pengguna untuk melakukan percobaan terhadap inovasi baru (triability).

Keputusan pembelian konsumen mengacu pada berbagai orientasi dan perspektif. Konsumen merujuk pada bagaimana berbagai orientasi mempengaruhi adanya niat, proses keputusan pembelian dan perilaku pembeli secara keseluruhan. Perilaku konsumen adalah studi tentang proses yang terlibat ketika individu atau kelompok memilih, membeli, menggunakan atau membuang produk, layanan, ide atau pengalaman untuk memenuhi kebutuhan dan keinginan (Solomon 1996 dalam Prasad, et. al 2014). Pengambil keputusan konsumen berhubungan dengan pengambilan keputusan tentang penawaran produk dan layanan. Hal ini dapat didefinisikan sebagai proses pengumpulan informasi, mengevaluasi dan memilih opsi terbaik untuk memecahkan masalah atau membuat pilihan pembelian

Schiffman \& Kanuk (2004) mendefinisikan keputusan sebagai suatu pemilihan tindakan dari dua atau lebih pilihan alternatif. Pengambilan keputusan individu dalam mengkonsumsi produk tertentu dilakukan dengan dua tahap, yaitu editing dan evaluation. Pada tahap editing, seorang individu menyederhanakan pengambilan keputusan dengan mempertimbangkan konsekuensi keuntungan dan kerugian. Tahap kedua, evaluation, yaitu mengevaluasi alternatif dengan menghitung nilai dari tiap alternatif dan memilih alternatif dengan nilai tertinggi (Mowen dan Minor, 2001 dalam Ikhdar, 2006)

Berbagai penelitian yang telah dilakukan sebelumnya memberikan gambaran bahwa tingkat adopsi teknologi dapat mempengaruhi secara positif terhadap sikap dan keinginan untuk memakai layanan Fintech dan servis teknologi lainnya (Chuang, Liu \& Kao, 2016; Cheung \& Vogel, 2013). Demikian juga dengan persepsi manfaat dan kemudahan penggunaan teknologi masyarakat muslim di Malaysia terhadap pemakaian cash waqf platform, investment account portfolio, menunjukan pengaruh yang positif (Thaker, M. A., Thaker, H, \& Pitchay,2018, Thaker, M. A., \& Thaker, H,2017). 


\section{Kerangka Pemikiran Konseptual}

Sehingga berdasarkan tinjauan pustaka, penelitian ini membuat hipotesis sebagai berikut:

H1: Kerangka model hipotesis penelitian dapat digunakan dengan variabel laten sesuai dengan Technology Adoption Model.

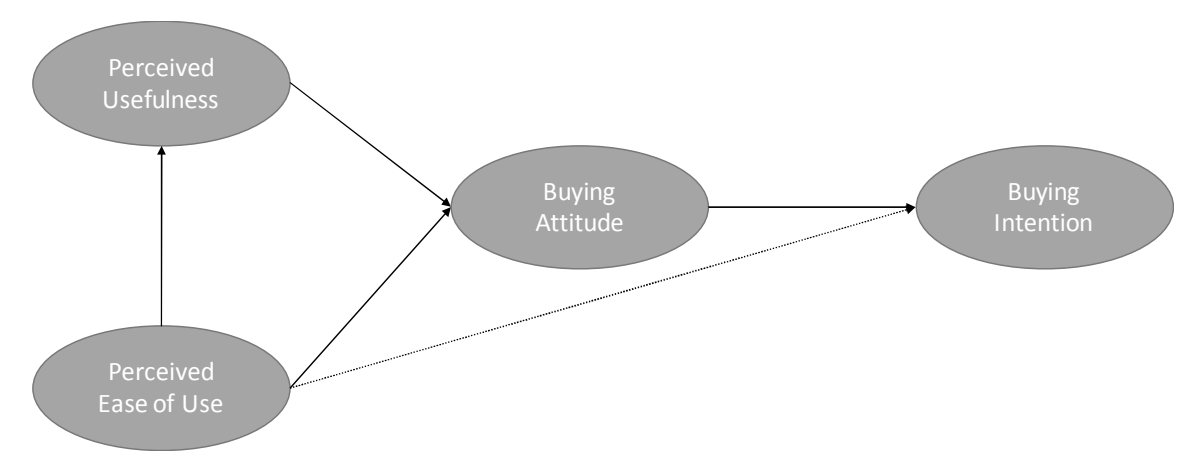

Gambar 1. Model Hipotesis Penelitian

H2: $\quad$ Adopsi teknologi (Perceived Usefulness dan Perceived of Ease of Use) memiliki pengaruh signifikan terhadap pembentukan sikap terhadap produk Fintech syariah

H3: Sikap terhadap produk Fintech syariah menjadi mediator antara adopsi teknologi dengan intensi muslim melakukan investasi

H4: Sikap terhadap produk Fintech syariah memiliki pengaruh signifikan terhadap intensi muslim dengan produk investasi Fintech.

\section{METODE PENELITIAN}

\section{Responden dan Data Sampel}

Data perilaku muslim diambil berdasarkan jumlah sampel yang ditentukan menggunakan software A-priori oleh Soper, D.S. (2018) berdasarkan lower bound sample size, metode yang dilakukan oleh Christopher Westland (2010). Anticipated effect size menggunakan 0.3 untuk ukuran medium dan desired statistical power level dengan standar 0.8. Berdasarkan hipotesis model yang digunakkan dalam TAM dibutuhkan empat variabel laten dan 16 variabel observasi dengan level probabilitas sebesar 0.05. Maka, direkomendasikan minimal sampel untuk struktur model adalah 100 sedangkan untuk mengetahui efek SEM dibutuhkan minimal 137 jumlah sampel. Tanggapan yang didapatkan 
berjumlah 189 orang, sehingga cukup berdasarkan perhitungan A-priori. Pengambilan sampel dilakukan secara acak namun beragama Islam.

\section{Instrumen Penelitian}

Pertanyaan penelitian terdiri dari profil responden, perceived of usefulness, perceived ease of use, buying attitude, dan buying intention untuk produk Fintech syariah. Masingmasing variabel observasi didapatkan dari penelitian sebelumnya mengenai adopsi teknologi terhadap servis Fintech dan perilaku pembelian muslim terhadap produk keuangan sebagai pedoman pembentukan kuesioner yang dilakukan oleh Chuang, Liu, \& Kao (2016) dan Sharma, Newaz, \& Fam (2017).

\section{Pengujian Model Penelitian}

Model diuji melalui dua tahap yaitu exploratory factor analysis (EFA) dan confirmatory factor analysis (CFA) untuk mengukur model, struktur, atau analisis jalur. Metode SEM ini memungkinkan peneliti untuk menilai dan memodifikasi model teoritis, yang memberikan peluang untuk mengeksplorasi perkembangan hubungan baru dalam model untuk teori penelitian (Anderson, James C., Gerbing David, 1988). Agar memastikan loading factor yang dimiliki cukup kuat untuk membentuk variabel laten penelitian ini menggunakan pendekatan dua tahap tersebut.

\section{a. Pengujian Model Penelitian dengan Uji EFA}

Tahap pertama, variabel laten dan observasi pada model dianalisis menggunakan EFA untuk menguji variabel laten yang dapat menjelaskan adopsi teknologi muslim untuk produk Fintech syariah dengan menggunakan factor analysis extraction, eigenvalues, varimax, scree plot dan rotated component matrix (Fabrigar, L. R., \& Wegener, D. T.,2011)

\section{b. Pengujian Model Penelitian dengan Uji CFA}

Uji CFA bertujuan untuk mengukur model yang akan digunakan sebelum melakukan analisis dua kerangka penelitian dengan SEM. Penelitian ini menggunakan maximum likelihood sebagai metode estimasi di semua analisis SEM. Dilakukan uji undimensionality, validitas berupa construct, convergent dan discriminant, kemudian uji normalitas. Chi-square, ratio of chi-square to degrees of freedom $(d f \mathrm{~s})$, root mean square 
error of approximation (RMSEA), standardized root mean square residual (RMR), goodness-of-fit index (GFI), normed fit index (NFI), dan comparative fit index (CFI) adalah pengukuran yang digunakan untuk analisis validitas (Zainudin, A.,2014).

\section{Analisis Data Penelitian}

Perilaku dari potensial investor untuk menggunakan produk Financial Technology Islam diuji menggunakan Structural Equation Modeling (SEM). SEM memudahkan untuk menguji beberapa hubungan dependen secara simultan yang memiliki banyak persamaan juga uji mediator lebih baik dibandingkan regresi biasa. Pada penelitian ini menggunakan aplikasi SPSS-AMOS.

\section{HASIL DAN PEMBAHASAN}

\section{Profil Sampel Penelitian}

Sebanyak 189 responden muslim telah didapatkan melalui kuesioner online dalam kurun waktu lima hari. Profil responden memiliki proporsi yang cukup seimbang yaitu 48,1\% laki-laki dan 51,9\% perempuan. Mayoritas responden merupakan Gen Y (millenials) yaitu $20-<35$ tahun sebesar $86,8 \%,>35-<50(7,9 \%)$, dan $<20$ tahun dan $>50$ tahun masing-masing 2,6\%.

Sebanyak $63,1 \%$ responden belum menikah, 36\% sudah berkeluarga, dan 1,1\% berstatus janda/duda. Pendapatan bervariatif dari $<5$ juta sebesar 42,9\%, 15-25 juta (39,2\%), 5-15 juta (12,7\%) dan $>25$ juta (5,3\%). Sedangkan, responden cukup berpendidikan dikarenakan $81 \%$ telah menyelesaikan Strata-1 (S1), 10,6\% lulusan SMP/SMA dan 8,5\% telah lulus Strata-2 (S2). Informasi lainnya, sebanyak 55,6\% responden telah melakukan investasi dan $44,4 \%$ belum pernah melakukan investasi meskipun dalam bentuk tabungan dan deposito. Pendapatan yang dialokasikan untuk investasi juga beragam, sebanyak $22,8 \%$ pada rentang $>10 \%-20 \%, 11,1 \%$ pada rentang $>20 \%-30 \%$, dan mayoritas kurang dari $10 \%$ (63,5\%) termasuk 83 responden yang tidak pernah melakukan investasi. 
Tabel 1. Profil Responden Penelitian

\begin{tabular}{|c|c|c|}
\hline \multicolumn{3}{|l|}{ Variabel } \\
\hline Jenis Kelamin & Frekuensi & Proporsi (\%) \\
\hline Laki-laki & 91 & 48,1 \\
\hline Perempuan & 98 & 51,9 \\
\hline \multicolumn{3}{|l|}{ Kelompok Umur } \\
\hline$<20$ Tahun & 5 & 2,6 \\
\hline $20-<25$ th & 89 & 47,1 \\
\hline $25-<35$ th & 75 & 39,7 \\
\hline $35-50$ th & 15 & 7,9 \\
\hline$>50$ th & 5 & 2,6 \\
\hline \multicolumn{3}{|l|}{ Status } \\
\hline Menikah & 68 & 36 \\
\hline Belum menikah & 119 & 63,1 \\
\hline Duda/Janda & 2 & 1,1 \\
\hline \multicolumn{3}{|l|}{ Pendapatan } \\
\hline$<5$ juta & 81 & 42,9 \\
\hline 5-15 juta & 24 & 12,7 \\
\hline $15-25$ juta & 74 & 39,2 \\
\hline$>25$ juta & 10 & 5,3 \\
\hline \multicolumn{3}{|l|}{ Pendidikan } \\
\hline SMP/SMA & 20 & 10,6 \\
\hline Strata-1 (S1) & 153 & 81 \\
\hline Strata-2 (S2) & 16 & 8,5 \\
\hline
\end{tabular}

Sumber : Kuesioner, data diolah

\section{Pengujian Model Hipotesis}

Untuk menguji variabel laten, digunakan analisis faktor dengan Principal Component Analysis, Scree Plot, dan rotated component menggunakan Varimax. Berdasarkan EFA, model yang akan diuji melalui CFA sebelum SEM berada pada gambar 2. Sehingga Hipotesis 1, ditolak dan menggunakan model baru untuk pengujian SEM. Oleh karena itu, pada hipotesis ketiga asumsi faktor mediasi menjadi variabel laten Technology Adoption (TA) terhadap Buying Intention (BI)

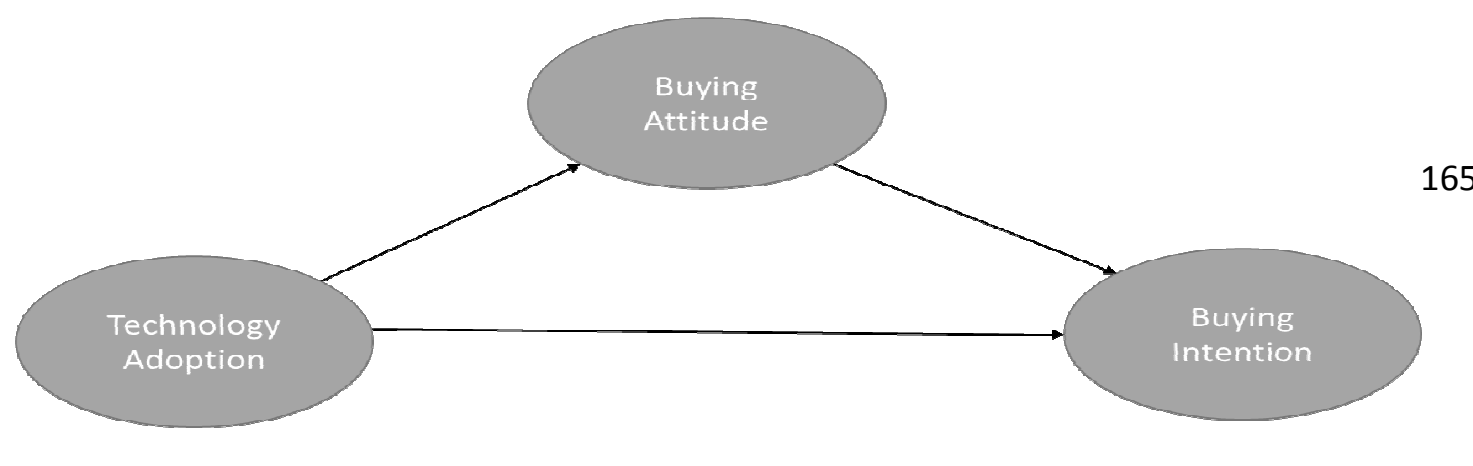




\section{Gambar 2. Model Uji SEM}

Berdasarkan analisis faktor, variabel Perceive Usefulness dan Perceive Ease of Use menjadi satu variabel laten berdasarkan rotated component matrix. Model penelitian menjadi lebih sederhana tanpa mengurangi reabilitas dari setiap variabel laten. Factor loading yang dimiliki masing-masing variable berada di atas $>0,7$, memiliki Cornbach alpha dalam rentang 0,86-0,94, dan KMO dan Bartlett Test yang signifikan. Sehingga dapat disimpulkan, model uji SEM dapat dilanjutkan pada tahap berikutnya yaitu CFA yang akan dijalankan pada SPSS-AMOS.

Tabel 2. Hasil Exploratory Factor Analysis - Model 1

\begin{tabular}{|c|c|c|c|c|c|}
\hline \multicolumn{6}{|c|}{ Exploratory Factor Analysis } \\
\hline Technology Adoption & Mean & Loading & Eigenvalue & $\begin{array}{c}\text { Variance } \\
\text { Explained (\%) }\end{array}$ & $\begin{array}{c}\text { Cronbach's } \\
\text { alpha }\end{array}$ \\
\hline PU1 1 & 4,03 & 0,739 & 5,078 & 31,736 & 0,941 \\
\hline PU2 & 4,04 & 0,813 & & & \\
\hline PU3 & 3,95 & 0,812 & & & \\
\hline PU4 & 3,82 & 0,793 & & & \\
\hline PEOU 1 & 3,91 & 0,875 & & & \\
\hline PEOUZ & 3,66 & 0,823 & & & \\
\hline PEOU3 & 3,68 & 0,836 & $\begin{array}{r}\text { KMO \& } \\
\text { Adequacy: }\end{array}$ & $\begin{array}{l}\text { Bartlett Test } \\
\text {,898; Sig.,OOO }\end{array}$ & \\
\hline \multicolumn{6}{|l|}{ Buying Attitude } \\
\hline $\mathrm{BA} 1$ & 3,81 & 0,802 & 2,817 & 17,606 & 0,856 \\
\hline BA2 & 3,95 & 0,807 & & & \\
\hline $\mathrm{BA} 3$ & 3,99 & 0,744 & & & \\
\hline \multirow[t]{2}{*}{$\mathrm{BA} 4$} & 4,14 & 0,582 & & & \\
\hline & & & $\begin{array}{l}\text { KMO \& } \\
\text { Adequacy }\end{array}$ & $\begin{array}{l}\text { Bartlett Test } \\
81 . \text { Sig }\end{array}$ & \\
\hline \multicolumn{6}{|l|}{ Buying Intention } \\
\hline BI1 & 4,01 & 0,755 & 3,795 & 23,719 & 0,895 \\
\hline $\mathrm{BI} 2$ & 3,79 & 0,785 & & & \\
\hline BI3 & 3,85 & 0,736 & & & \\
\hline BI4 & 3,79 & 0,800 & KMO \& & Bartlett Test & \\
\hline BI5 & 3,7 & 0,702 & Adequacy: & ,875; Sig. ,000 & \\
\hline
\end{tabular}

Sumber : Kuesioner, data diolah

Berikutnya adalah pengujian CFA untuk mengetahui goodness-fit pada suatu model penelitian sebelum melakukan analisis SEM. Dilakukan analisis CFA yang menghasilkan Chi-Square yang sangat tinggi, walaupun sudah melakukan indeks modifikasi, sehingga dilakukan uji normalitas pada setiap variabel yang menghilangkan variabel PU2 "Manfaat Fintech dalam melakukan transaksi" dikarenakan memiliki kurtosis $>3.00$. Begitu juga dengan BI3 "Kesadaran risiko" dikeluarkan dari model untuk mengoptimalkan discriminant validity. Kemudian, berdasarkan analisis model fit, baik P- 
value, RMSEA, GFI, RMR, NFI, dan CFI telah sesuai standar masing-masing indeks. (Wheaton et al.,1977; Browne and Cudeck,1993; Joreskog and Sorbom, 1984; Bentler,1990; Bollen, 1989; Marsh and Hocevar, 1985).

Tabel 3. Hasil Indeks Model Fit - Model 1

\begin{tabular}{lcccccc}
\hline Model & P-value & RMSEA & GFI & RMR & NFI & CFI \\
\hline TA_1 & 0,102 & 0,035 & 0,946 & 0,037 & 0,961 & 0,992 \\
Baseline & $>0,05$ & $<0,08$ & $>0,9$ & $<0,08$ & $>0,9$ & $>0,9$ \\
& $*$ All indices supported & & & & \\
\hline
\end{tabular}

Sumber : Kuesioner, data diolah

Demikian juga berdasarkan CFA, tiap-tiap variabel memiliki standardized loading, AVE, dan CR di atas $>0,6$. Sehingga model yang diajukan memenuhi construct dan convergent validity yang dibutuhkan dalam pengujian model penelitian.

Tabel 4. Hasil Critical Factor Analysis - Model 1 


\begin{tabular}{|c|c|c|c|c|}
\hline \multicolumn{5}{|l|}{ Critical Factor Analysis } \\
\hline Technology Adoption & Mean & $\begin{array}{l}\text { Standardized } \\
\text { Loading }\end{array}$ & AVE & $\begin{array}{l}\text { Composite } \\
\text { Reliability }\end{array}$ \\
\hline PU 1 & 4,03 & 0,780 & 1,722 & 0,991 \\
\hline PU2 & 4,04 & $* * *$ & & \\
\hline PU3 & 3,95 & 0,850 & & \\
\hline PU4 & 3,82 & 0,830 & & \\
\hline PEOU 1 & 3,91 & 0,910 & & \\
\hline PEOU2 & 3,66 & 0,770 & & \\
\hline PEOU3 & 3,68 & 0,770 & & \\
\hline \multicolumn{5}{|l|}{ Buying Attitude } \\
\hline $\mathrm{BA} 1$ & 3,81 & 0,690 & 0,673 & 0,977 \\
\hline $\mathrm{BA} 2$ & 3,95 & 0,740 & & \\
\hline $\mathrm{BA} 3$ & 3,99 & 0,820 & & \\
\hline BA4 & 4,14 & 0,810 & & \\
\hline \multicolumn{5}{|l|}{ Buying Intention } \\
\hline BI1 & 4,01 & 0,780 & 0,768 & 0,988 \\
\hline $\mathrm{BI} 2$ & 3,79 & $* * *$ & & \\
\hline $\mathrm{BI} 3$ & 3,85 & 0,850 & & \\
\hline BI4 & 3,79 & 0,830 & & \\
\hline BI5 & 3,7 & 0,820 & & \\
\hline
\end{tabular}

Discriminant Validity

\begin{tabular}{cccc}
\hline & TA $(1,607)$ & $\mathrm{BA}(0,624)$ & $\mathrm{BI}(1,040)$ \\
TA & 1 & & \\
& & & \\
BA & 0,554 & 1 & \\
SC & $(0,307)$ & & 1 \\
BI & 0,584 & 0,802 & \\
SC & $(0,341)$ & $(0,643)$ & \\
& & & \\
\hline
\end{tabular}

Sumber : Kuesioner, data diolah

Tahap berikutnya adalah melihat discriminant validity untuk mengetahui hubungan antara variabel laten agar tidak terjadi tumpang tindih di antarannya dalam satu model. Terdapat dua cara untuk menentukan validitas tersebut yaitu, dengan mengkomparasikan kuadrat dari korelasi antara variabel dengan nilai variabel laten utama. Untuk memastikannya, squared correlation < AVE (Fomell \& Larcker, 1981). Namun, ada cara kedua yaitu jika korelasi antara dua variabel laten $>0.9$ (Hiar,et. al, 2010) maka keduanya memiliki konstruksi yang bertumpang tindih secara signifikan, sehingga multikolinearitas terjadi. Pada penelitian ini, menurut pengujian $\mathrm{SC}<\mathrm{AVE}$ semua 
variabel laten sesuai konstruksi validitas, diperkuat lagi berdasarkan Hiar,et. al, (2010) bahwa korelasi antar variabel tidak signifikan dikarenakan hubungan antar variabel laten $<0,9$.

Untuk uji normalitas multivariate, model ini belum memenuhi asumsi distribusi normal. Dikarenakan penelitian ini menggunakan Maximum Likelihood Estimation dengan AMOS yang merupakan robust estimator yang tetap dapat bekerja secara robust walaupun asumsi distribusi data tidak sesuai (Zainudin, 2014). Namun ada beberapa perihal yang harus diperhatikan yaitu analisis kurtosis dan skewness. Model ini dapat dilanjutkan ke tahap analisis dikarenakan cr. kurtosis tidak $>3,00$ dan cr. skewness tidak $>8,00$.

\section{Hasil Analisis Model Struktural}

Setalah diuji dengan beberapa parameter SEM, dilakukan analisis jalur dan efek untuk pengujian hipotesis penelitian mengenai adopsi teknologi, sikap, dan intensi muslim terhadap produk Fintech syariah.

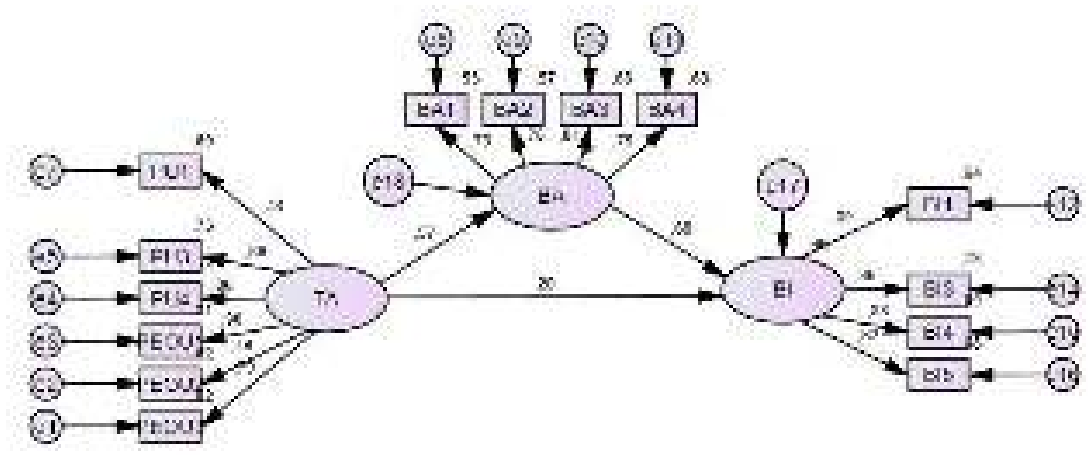

Gambar 3. Model Struktural Penelitian

Sumber : Kuesioner, data diolah

Tabel 6. Hasil Model Struktural - TA_1 
Structural Equation Modeling - No Mediation

\begin{tabular}{|c|c|c|c|c|c|c|}
\hline Mediation & Relationship & Estimate & S.E. & C.R & P-Value & \\
\hline Direct Effect & TA -> BI & 0,561 & 0,080 & 6,972 & $* * *$ & \\
\hline \multicolumn{7}{|c|}{$\begin{array}{l}\text { Structural Equation Modeling - TA_1 - } \\
\text { With Mediation }\end{array}$} \\
\hline Hypothesis & Relationship & Estimate & S.E. & C.R & P-Value & Decision \\
\hline $\mathrm{H} 2$ & TA -> BA & 0,465 & 0,074 & 6,309 & $* * *$ & Supported \\
\hline H3 & TA $->$ BI & 0,193 & 0,068 & 2,854 & 0,004 & Supported \\
\hline $\mathrm{H} 4$ & $\mathrm{BA}->\mathrm{BI}$ & 0,791 & 0,112 & 7,034 & $* * *$ & Supported \\
\hline
\end{tabular}

Berdasarkan analisis SEM dapat disimpulkan terjadi hubungan positif signifikan antara variabel TA dengan BA maka hipotesis kedua dapat diterima. Setelah melakukan pengujian pada variabel laten TA dengan BI memiliki direct effect yang signifikan, diketahui memiliki $\beta=0,561$ tanpa mediator $\mathrm{BA}$. Kemudian $\beta(\mathrm{TA})=0,193$ menurun ketika variabel laten BA masuk ke dalam model menandakan ada efek mediasi BA terhadap TA dan BI. Dikarenakan mediasi yang parsial, TA -> BI $(\mathrm{p}<0,01)$ maka variabel TA memiliki hubungan efek langsung yang signifikan terhadap BI dan hubungan tidak langsung yang signifikan melalui BA terhadap BI (Zainudin, 2015). Oleh karena itu, hipotesis ketiga diterima. Demikian juga dengan hubungan BA terhadap BI yang signifikan sehingga hipotesis keempat diterima.

\section{Analisis Deskriptif Variabel Observarsi}

Dari masing-masing variabel observasi dari 189 sampel memiliki persepsi manfaat yang cukup positif terhadap efisiensi Fintech dalam transaksi dan informasi $(\overline{\mathrm{X}}=3,95$ 4,03). Namun, untuk kemudahan mempelajari cara penggunaan Fintech masih berada di bawah $\bar{X}=3,88$ yaitu $3,66-3,68$. Dengan $44,4 \%$ orang yang belum pernah melakukan investasi, sikap ketertarikan responden dengan ide produk Fintech syariah tinggi $\overline{\mathrm{X}}=4,14$ dan sikap responden terhadap produk investasi Fintech syariah terbilang positif $(\overline{\mathrm{X}}=3,81$ - 
4,14). Begitu juga dengan ketertarikan untuk berinvestasi melalui Fintech syariah berada di atas rata-rata yaitu $\overline{\mathrm{X}}=4,01$ dan sikap advokasi terhadap investasi syariah sebesar $\overline{\mathrm{X}}=3,85$ dengan $\mathrm{SL}=0,850$.

\section{Tabel 7. Analisis Deskriptif Variabel Observasi}

\begin{tabular}{llcc}
\hline Technology Adoption & Mean & $\begin{array}{c}\text { Standardized } \\
\text { Loading }\end{array}$ \\
PU1 & FinTech lebih efisien & 0.780 \\
PU3 & Informasi investasi lebih cepat & 4.03 & 0.850 \\
PU4 & Investasi lebih tepat dan kontribusi positif & 3.95 & 0.830 \\
PEOU1 & Mudah menggunakan FinTech & 3.82 & 0.910 \\
PEOU2 & Mudah tanpa manual dan bantuan orang lain & 3.91 & 0.770 \\
PEOU3 & Mudah belajar menggunakan tanpa waktu yang lama & 3.66 & 0.770 \\
& & 3.68 & 0.690 \\
Buying Attitude & & & 0.740 \\
BA1 & FinTech syariah beroperasi sesuai dengan hukum Islam & 3.81 & 0.820 \\
BA2 & Mengikuti prinsip bebas bunga atau riba & 3.95 & 0.810 \\
BA3 & Memiliki prinsip pembagian keuntungan dan risiko & 3.99 & \\
BA4 & Menyukai ide menggunakan layanan FinTech syariah & 4.14 & \\
& & & 0.790 \\
Buying Intention & & & 0.850 \\
BI1 & Ketertarikan melakukan investasi FinTech syariah & & 0.830 \\
BI3 & Akan merekomendasikan kepada orang lain & 4.01 & 0.810 \\
BI4 & Menerima semua risiko & 3.85 & 3.79 \\
BI5 & Pilihan utama dalam berinvestasi & 3.70 & \\
& & & \\
\hline
\end{tabular}

Sumber : Kuesioner, data diolah

\section{SIMPULAN}

Dalam model persamaan struktural ini menggambarkan bahwa adopsi teknologi pada sisi kemudahan dan manfaatnya memengaruhi secara signifikan intensi untuk menggunakan produk invetasi Fintech berbasis syariah. Di sisi lain, sikap terhadap produk Fintech syariah memberikan efek tidak langsung yang signifikan untuk tingkat adopsi teknologi untuk menentukan intensi masyarakat dalam melakukan investasi pada produk Fintech syariah dengan signifikan yang sedikit lebih tinggi. 
Agar calon investor mau melakukan investasi pada produk Fintech, dibutuhkan pengembangan edukasi dalam pemakaian aplikasi mobile atau web untuk memudahkan investor mempelajari produk Fintech tanpa bantuan orang lain. Pengembangan user interface dan user experience sangat dibutuhkan untuk meningkatkan adopsi teknologi dari potensial investor yang akan meningkatkan pembelian produk investasi Fintech syariah. Walaupun mayoritas masyarakat Indonesia adalah muslim, Fintech syariah masih kurang umum dalam masyarakat walaupun memiliki sikap yang positif terhadap produk Fintech syariah.

Banyaknya keterbatasan pada model dikarenakan proses penelitian yang memiliki kurun waktu yang singkat. Penelitian ini membutuhkan sampel yang sangat besar dikarenakan konsep Fintech masih kurang umum pada masyarakat Indonesia agar responden memiliki distribusi yang mendekati atau normal. Formulasi kuesioner yang lebih terstruktur seperti validasi dari hasil wawancara antara ahli Fintech dan calon investor sangat dibutuhkan walaupun reabilitas pada variabel penelitian ini tinggi. Pada penelitian ini hanya memberikan contoh beberapa Fintech di Indonesia. Untuk penelitian selanjutnya sangat dibutuhkan penjelasan apa yang dimaksud skema investasi melalui Fintech secara lisan dan bentuk simulasi. Sehingga, variabel adopsi teknologi akan terefleksikan lebih baik dalam penilaian responden. Akan lebih baik lagi jika penelitian selanjutnya menambahkan faktor religiositas baik secara indeks atau efek priming mengenai riba dan investasi Islam untuk mengetahui actual behavior dengan skema pengambilan data kuesioner secara dua tahap.

\section{DAFTAR PUSTAKA}

Aaron, M., Rivadeneyra, F., and Sohal, S.(2017). Fintech : Is this time different? A framework for assessing risks and opportunities for Central Banks. Bank of Canada Staff Discussion Paper 2017-10 (July). Canada : Bank of Canada

Anderson, James C., Gerbing David, W. (1988). Structural Equation Modeling in Practice: A Review and Recommended Two-Step Approach. Psychological Bulletin, 103(3), 411-423. https://doi.org/10.1037/0033-2909.103.3.411 
Ario, Arresto. (2007). Analisis Faktor-Faktor Penentu Tingkat Adopsi Teknologi Baru Untuk Meningkatkan Peluang Penerimaan Produk di Pasar Telekomunikasi Seluler. Universitas Indonesia, Depok.

Arner, D.W., Barberis, J., and Buckley, R.P.(2015). The evolution of FinTech : A new postcrises paradigm?. University of Hong Kong.

Asytuti, Rinda. (2003). Analisis Perbandingan Kinerja Antara Reksa Dana Syariah dan Reksa Dana Konvensional dalam Menghasilkan Return Optimal. Tesis. Jakarta: Universitas Indonesia

Christopher Westland, J. (2010). Lower bounds on sample size in structural equation modeling. Electronic Commerce Research and Applications, 9(6), 476-487. https://doi.org/10.1016/j.elerap.2010.07.003

Chuang, L.-M., Liu, C.-C., \& Kao, H.-K. (2016). The Adoption of Fintech Service: TAM perspective. International Journal of Management and Administrative Sciences (IJMAS) (IJMAS), 3(07), 2225-722501. https://doi.org/10.1103/PhysRevLett.111.093902

Fabrigar, L. R., \& Wegener, D. T. (2011). Exploratory factor analysis : exploratory factor analysis. Retrieved from https://remote-lib.ui.ac.id:2195

Fauzi, Achmad. (2017) Kompas.com dengan judul "OJK: "Fintech P2P Lending" di Indonesia Capai $R p \quad 1,6 \quad$ Triliun", Available from https://ekonomi.kompas.com/read/2017/11/09/193700626/ojk-fintech-p2p-lendingdi-indonesia-capai-rp-16-triliun.

Financial Stability Board (FSB, 2017a). FinTech credit : Market structure, business models and financial stability implications. May 2017

Garg, Naina. Financial technology adoption and the dynamics of capital market development: A cross-country examination. Halifax, Nova Scotia. 2017

Hadi, Rosmaya. Regulasi Ekonomi dalam Meningkatkan Pembangunan di Daerah dalam https://www.bi.go.id/id/institute/kegiatan/kuliah-umum/Contents/Materi Kuliah Umum USU.pptx diunduh Kamis 1 November 2018, pukul 13.40

Heykal, Mohamad. (2012). Tuntunan Aplikasi Investasi Syariah. Jakarta. Elex Media Komputindo 
Ikhdar, Andi. (2006). Pengaruh Performance, Informasi dan Merek Produk terhadap Kepuasan dan Penyelesaian Serta Hubungannya dengan Niat Pembelian Ulang. UI, Depok.

Irkhami, Nafis. 2010. Analisis Risiko dalam Investasi Islam. Salatiga: Jurnal Muqtasid STAIN Salatiga

Mohamed Asmy Mohd Thas Thaker, Hassanudin Mohd Thas Thaker, Anwar Allah Pitchay, (2018) "Modeling crowdfunders' behavioral intention to adopt the crowdfunding-waqf model $(\mathrm{CWM})$ in Malaysia: The theory of the technology acceptance model", International Journal of Islamic and Middle Eastern Finance and Management, Vol. 11 Issue: 2, pp.231-249, https://doi.org/10.1108/ IMEFM-062017-0157

Mohd Thas Thaker, M. A., \& Mohd Thas Thaker, H. (2017). The behavioral intention of investors to use Islamic banking's Investment Account Platform (IAP) as a source of investment portfolio: a structural equation modelling approach. Journal of Islamic Monetary Economics and Finance, 3(1), $113 \quad$ - 138. https://doi.org/10.21098/jimf.v3i1.712

Prasad, Ram Komal. K Jha, Manoj. (2014) Consumer buying decisions models: A descriptive study. Mumbai, India: National Institute of Industrial Engineering (NITIE)

PricewaterhouseCoopers Research. (2017). Financial Services Technology 2020 and Beyond: Embracing disruption. Retrieved from https://www.pwc.com/gx/en/financial-services/assets/pdf/technology2020-andbeyond.pdf.

Ridwan S. Sundjaja dan Inge Barlian, 2002, Manajemen Keuangan Satu, Edisi Keempat, Prenhallindo, Jakarta.

Schiffman, Leon G. and Kanuk (2004). Consumen Behavior, 8th Edition. New Jersey: Perason Pretice Hall.

Sharma, R. R., Newaz, F. T., \& Fam, K. S. (2017). Muslim religiosity, generational cohorts and buying behaviour of Islamic financial products. Australian Journal of Management, 42(3), 482-501. https://doi.org/10.1177/0312896216659530

Shorfer, Boris. (2017). FinTech Adoption Has Surged Globally Over the Past 18 Months. Available from https://ianmartin.com/fintech-adoption-surged-globally-past-18months/. 
Soper, D.S. (2018). A-priori Sample Size Calculator for Structural Equation Models [Software]. Available from http://www.danielsoper.com/statcalc

Tornatzky, L. G., dan Fleischer, M. (Eds.). (1990). The Process of Technological Innovation. Lexington, MA: Lexington Books.

Westland, J.C. (2010). Lower bounds on sample size in structural equation modeling. Electronic Commerce Research and Applications, 9(6), 476-487

Zainudin, A. (2014). Validating the measurement model: CFA. In A handbook on structural equation modeling (pp. 54-73). MPWS Rich Resources.

Zainudin, A. (2015). Analyzing the mediating variable in a model. In SEM Made Simple (pp. 101-133). MPWS Rich Resources. 